\title{
Can Canada get on with national pharmacare already?
}

$\mathrm{C}$ anadian political leaders, regardless of ideology, have all learned to pledge allegiance to the principle of a universal public health care system. But in terms of tangible commitments, federal leaders only seem prepared to throw more money into transfer payments to provinces and territories rather than consider real changes to address gaps in the quality of care.

Chief among these is the absence of a national pharmacare program. Plainly stated, our elected officials will fail to deliver on the promise of better-quality, accessible care for Canadians without making necessary drugs available to all.

Canada is the only country among its public health system peers throughout Europe, Australia and New Zealand not to have such a program. ${ }^{1}$ Canadians are served instead by a patchwork of widely varying provincial and territorial programs. What's covered for some is often unavailable to others. Today, only half of Canadians have coverage through employers, ${ }^{2}$ and only $60 \%-75 \%$ of Canadians have some form of private insurance. ${ }^{3}$ In an international survey, Canada came second only to the United States in terms of personal drug costs, with over $11 \%$ of the sickest Canadians paying more than $\$ 1000$ out-of-pocket per year for medications. ${ }^{4}$

The inevitable consequence is that some people are prevented from getting the drugs they need, and others do not take all the medications as prescribed. Failing to adhere to prescribed treatments contributes to excess morbidity and mortality, ${ }^{5}$ which in turn frustrates efforts to reduce the burden of disease and increases demands on the health care system.

It is not just patients who suffer from this gap in care. The country pays a price. Despite some improvements in health and quality of life, Canada's drug costs are rising faster than any other member country of the Organisation for Economic Cooperation and Development, at a rate close to $10 \%$ per year. ${ }^{2}$ Our disorganized management of pharmaceutical care makes drugs one of the most substantial cost drivers in the health system and a serious threat to medicare over the long term.

Pharmaceuticals are the fastest-growing portion of health care spending. But money is not the problem - it's how we choose to spend it on drugs. Although Canada spends more per capita on drugs than most other countries, including the United States, many of our scarce health dollars are misdirected to "me-too" drugs supplied by pharmaceutical companies or drained off by the insurance companies that supply private coverage. The money that goes to them is not available to support equitable, accessible high-quality care across the country. But that is not an accident: successive federal and provincial governments have created a system that artificially inflates the cost of drugs, by supporting copycat research with tax credits and favouring new drugs over older and cheaper (and often safer) alternatives. In addition, we don't have a national system for assessing drugs or a national formulary, which together would form a foundation for powerful bulk buying, potentially saving Canada as much as $\$ 10$ billion per year. ${ }^{2}$ We also lack an academic drug-detailing program to foster more appropriate and effective prescribing by physicians.

All these problems are well understood, and in response the National Pharmaceuticals Strategy was created as part of the 2004 federal-provincial health accord. ${ }^{6}$ It proposed the creation of a national formulary with common drug purchasing and pricing strategies, coverage of "catastrophic" drug costs for all Canadians, better evaluation of drug safety and effectiveness, improvements in the drug-approval process and more. Yet by 2011, shockingly little has been accomplished toward these goals.?

An obvious place to start is a commitment to long-term funding of pharmacare. This will generate the incentives to get an agreement on controlling costs through a coordinated, more competitive nationwide strategy for drug purchasing and pricing. Canada should also move immediately to create a single institution for evaluating medications, like the United Kingdom's National Institute for Health and Clinical Excellence, as a prerequisite for establishing a national formulary of proven and cost-effective drugs.

Canada's multiplicity of programs, which pay for drugs in health care institutions while often failing to pay for the same patients to receive the same drugs at home, make a mockery of the principles of medicare cherished by Canadians. We cannot pretend to have universal public health care or expect the benefits inherent in such a system while it excludes the medications necessary to prevent and treat illnesses.

Leadership means making the hard choices. In this instance, it means choosing between fostering the growth of Canada's pharmaceutical industry or improving and sustaining Canadian health care. Our leaders must decide, because the current approach fails on both counts.

We believe the public's choice would be health care. With Canadians suffering and, indeed, dying every day from inadequate drug coverage, and with a national pharmaceutical strategy already in place, the lack of action on pharmacare is inexcusable.

\section{Matthew B. Stanbrook MD PhD, Paul C. Hébert MD MHSc, Jane Coutts BA BAA, Noni E. MacDonald MD MSc, Ken Flegel MDCM MSc}

For references, see Appendix 1, available at www.cmaj.ca/lookup/suppl /doi:10.1503/cmaj.110643/-/DC1

Competing interests: See www.cmaj.ca/site/misc/cmaj_staff.xhtml. None declared by Jane Coutts.

Affiliations: See www.cmaj.ca/site/misc/cmaj_staff.xhtml. Jane Coutts is an Ottawa-based writer and editor and president of Coutts Communicates.

Correspondence to: $C M A J$ editor,pubs@cmaj.ca

CMAJ 2011. DOI:10.1503/cmaj.110643 